\title{
A Hospital Based Prospective Study to Assess the Prevalence of Iron Deficiency Anemia among Known Population
}

\author{
Hanuman Ram Choudhary', Mahipal Choudhary ${ }^{2}$

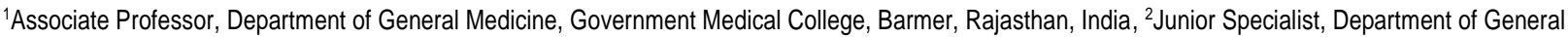 \\ Medicine, Government Medical College, Barmer, Rajasthan, India.
}

\section{Abstract}

Background: Iron deficiency anemia is a form of anemia due to the lack of sufficient iron to form normal red blood cells. Iron deficiency, the most common cause, is responsible for $50 \%$ of all anemias. Hence; we assessed the prevalence of iron deficiency anemia among known population. Subjects and Methods: The present research aimed for evaluating the prevalence of iron deficiency anemia. Sample size included assessment of a total of 220 patients who reported to the department of internal medicine of the hospital for routine medical checkup. A self-framed questionnaire was made and was given to all the subjects for collecting the demographic details. Blood samples were obtained from all the subjects and were sent to central laboratory for the assessment of blood hemoglobin levels. WHO criteria, described in the past literature, was used for categorizing the subjects with presence of iron deficiency anemia. All the results were analyzed by SPSS software. Results: Overall prevalence of iron deficiency anemia in the present study was found to be 11.36 percent. Majority of the subjects with iron deficiency anemia were found to be more than 35 years of age. Iron deficiency anemia was found to be more common among females and among illiterates. Conclusion: Iron deficiency anemia is a frequency encountered pathologic condition among general population, with especially high prevalence among females and illiterate population.

Keywords: Iron deficiency anemia, Prevalence.

Corresponding Author: Dr. Mahipal Choudhary, Junior Specialist, Department of General Medicine, Government Medical College, Barmer, Rajasthan, India.

Received: April 2019

Accepted: April 2019

\section{Introduction}

Anemia is defined by a decrease in the total amount of hemoglobin or the number of red blood cells. Iron deficiency anemia is a form of anemia due to the lack of sufficient iron to form normal red blood cells. Iron deficiency anemia is typically caused by inadequate intake of iron, chronic blood loss, or a combination of both. Iron deficiency anemia is the most common cause of anemia in the world. ${ }^{[1-3]}$ Approximately $25 \%$ of people worldwide have anemia. Iron deficiency, the most common cause, is responsible for $50 \%$ of all anemias. The rate of iron deficiency is higher in developing countries compared to the United States, where the prevalence of iron-deficiency anemia in men under 50 is $1 \% \cdot{ }^{[4-6]}$ Hence; under the light of above mentioned data, we planned the present study to assess the prevalence of iron deficiency anemia among known population.

\section{Subjects and Methods}

The present research aimed for evaluating the prevalence of iron deficiency anemia. The study was carried out in the department of General Medicine, Government Medical College, Barmer, Rajasthan, India. For carrying out the present study, we obtained ethical approval was obtained from institutional ethical committee and written consent from all the subjects, after explaining in detail the entire research protocol. Sample size included assessment of a total of 220 patients who reported to the department of internal medicine of the hospital for routine medical checkup.

\section{Exclusion criteria for the present study included:}

- Subjects with presence of any acute pathology,

- Subjects with presence of any other iron metabolic disorder,

- Diabetic and hypertensive subjects

A self-framed questionnaire was made and was given to all the subjects for collecting the demographic details. Blood samples were obtained from all the subjects and were sent to central laboratory for the assessment of blood hemoglobin levels. WHO criteria, described in the past literature, was used for categorizing the subjects with presence of iron deficiency anemia. ${ }^{[7-9]}$ All the results were analyzed by SPSS software. Chi- square test was used for 
assessment of level of significance. P- value of less than 0.05 was taken as significant.

\section{Results}

The present research aimed for evaluating the prevalence of iron deficiency anemia. Assessment of a total of 220 subjects was done in the present study. Mean age of the subjects with iron deficiency anemia was found to be 54.5 years. Overall prevalence of iron deficiency anemia in the present study was found to be 11.36 percent. Majority of the subjects with iron deficiency anemia were found to be more than 35 years of age. Iron deficiency anemia was found to be more common among females and among illiterates.

\section{Table 1: Prevalence of iron deficiency anemia}

\begin{tabular}{|l|l|l|}
\hline Parameter & Number & Percentage \\
\hline $\begin{array}{l}\text { Iron deficiency } \\
\text { anemia }\end{array}$ & 25 & 11.36 \\
\hline
\end{tabular}

Table 2: Age-wise distribution of iron deficiency anemia subjects

\begin{tabular}{|l|l|l|l|}
\hline Age group (years) & Number & Percentage & p- value \\
\hline Less than 35 & 5 & 2.27 & \multirow{2}{*}{0.55} \\
\cline { 1 - 3 } 35 to 55 & 10 & 4.54 & \\
\cline { 1 - 2 } More than 55 & 10 & 4.54 & \\
\hline
\end{tabular}

Table 3: Gender-wise distribution of iron deficiency anemia subjects

\begin{tabular}{|l|l|l|l|}
\hline Gender & Number & Percentage & p- value \\
\hline Males & 10 & 4.54 & 0.00 (Significant) \\
\hline Females & 15 & 6.81 & \\
\hline
\end{tabular}

Table 4: Prevalence of iron deficiency anemia among subjects divided on the basis of educational qualification

\begin{tabular}{|c|c|c|c|}
\hline $\begin{array}{l}\text { Educational } \\
\text { qualification }\end{array}$ & Number & Percentage & p- value \\
\hline Illiterate & 10 & 4.54 & \multirow{4}{*}{$\begin{array}{l}0.00 \\
\text { (Significant) }\end{array}$} \\
\hline $\begin{array}{l}\text { Less than } \\
\text { secondary }\end{array}$ & 10 & 4.54 & \\
\hline Upto graduation & 4 & 1.82 & \\
\hline Postgraduate & 1 & 0.45 & \\
\hline
\end{tabular}

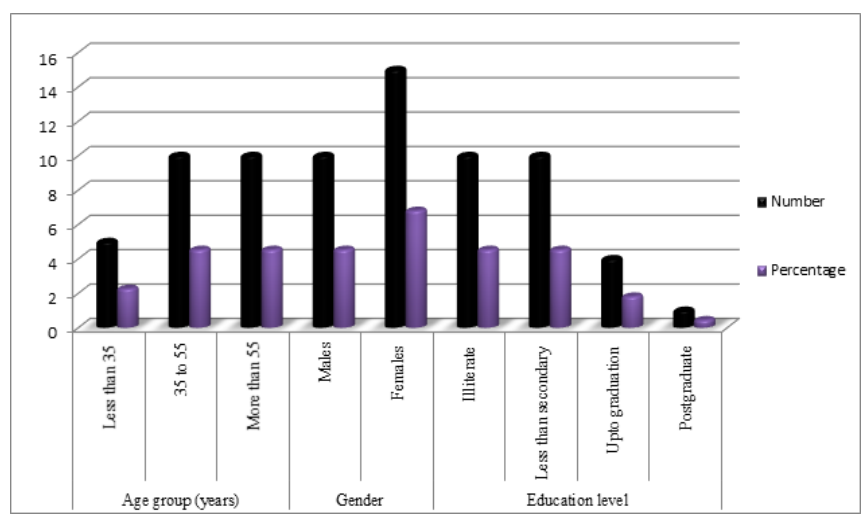

Figure 1: Age-wise, gender-wise and educational qualification -wise distribution of subjects with iron deficiency anemia

\section{Discussion}

Iron deficiency anemia arises when the balance of iron intake, iron stores, and the body's loss of iron are insufficient to fully support production of erythrocytes. Iron deficiency anemia rarely causes death, but the impact on human health is significant. In the developed world, this disease is easily identified and treated, but frequently overlooked by physicians. In contrast, it is a health problem that affects major portions of the population in underdeveloped countries. Overall, the prevention and successful treatment for iron deficiency anemia remains woefully insufficient worldwide, especially among underprivileged women and children. ${ }^{[7-9]}$ The present research aimed for evaluating the prevalence of iron deficiency anemia. Assessment of a total of 220 subjects was done in the present study. Mean age of the subjects with iron deficiency anemia was found to be 54.5 years. $\mathrm{Al}$-alimi $\mathrm{AA}$ et al determined the prevalence and risk factors of IDA among apparently healthy Yemeni students at Hodeida University. Five hundred blood samples (326 males and 174 females) were collected randomly from medical students at Hodeida University. Participants were subjected to different tests including complete blood counts (CBC), serum ferritin (SF), serum iron (SI), and total iron binding capacity (TIBC). Moreover, a questionnaire was designed to collect demographics, food and drink habits, and socioeconomic status. The overall prevalence of IDA was $30.4 \%$, of whom $54.00 \%$ were females and $46.0 \%$ were males. Students aged 20-22 years were found more anemic with prevalence $59.2 \%$ than students aged 17-19 years $(25.0 \%)$ and $23-25$ years (15.8\%). Statistical analysis showed regularly having breakfast had significant ( $\mathrm{p}<$ 0.001) role in preventing development of IDA compared with irregularly having breakfast. Infrequent consumption of vegetables/fruits; meat, fish, chicken; tea drinking; low household income; smoking and khat (Catha edulis) chewing showed a significant role $(p<0.001)$ in provoking of IDA, whereas consumption of coffee and cola showed insignificant influence (; ) on IDA. This study revealed that the majority of university students, especially females, have IDA that might become worse by malnutrition, lifestyle habits, and lack of awareness. Their results suggested that IDA can be prevented by providing proper knowledge on the healthful diet, improved lifestyle, and harmful effect of IDA to the students. ${ }^{[10]}$

The World Health Organization defines anemia as a level of $\mathrm{Hb}$ below $13.0 \mathrm{~g} / \mathrm{dL}$ in male adults, below $12.0 \mathrm{~g} / \mathrm{dL}$ in female adults who are not pregnant, and below $11.0 \mathrm{~g} / \mathrm{dL}$ in pregnant women. Hb levels may vary across age and race, so care must be taken, particularly in the interpretation of borderline values. Furthermore, smokers and inhabitants of higher altitudes may have higher baseline $\mathrm{Hb}$ levels, and participation in endurance sports may alter Hb levels. ${ }^{[8,9]}$

Overall prevalence of iron deficiency anemia in the present study was found to be 11.36 percent. Majority of the subjects with iron deficiency anemia were found to be more than 35 years of age. Iron deficiency anemia was found to 
be more common among females and among illiterates. Abdel-Rasoul GM et al estimated the prevalence and identify possible risk factors of iron-deficiency anemia (IDA) among a representative sample of primary school children (6-11 years), Menoufia governorate. The study sample included 497 students (242 boys, 255 girls). Blood samples and questionnaires were collected through school visits. A complete blood count was performed on all collected samples, and a serum ferritin test was carried out for anemic ones. The prevalence of IDA was $25.6 \%$. The result showed that anemia was higher in children from urban areas $(63.8 \%)$ than rural areas (36.2\%) and in children from low and middle socioeconomic (59.1\%) backgrounds than those from high socioeconomic standard $(40.9 \%)$. There was a significant relationship between children without IDA and anemic children in dietary habits, school achievements, and manifestations related to anemia $(\mathrm{P}<0.05)$. From the results, they concluded that the prevalence of iron deficiency is high among general population; to combat this problem, a program should be implemented by the government, especially the Ministry of Education and Ministry of Health, targeting both children and their parents through different public media approaches. $^{[11]}$

\section{Conclusion}

From the above results, it can be concluded that iron deficiency anemia is a frequency encountered pathologic condition among general population, with especially high prevalence among females and illiterate population. Hence; we strongly recommend organization of health education programs for increasing the awareness of adverse events associated with iron deficiency anemia among general population.

\section{References}

1. Johnson-Wimbley TD, Graham DY. Diagnosis and management of iron deficiency anemia in the 21st century. Therap Adv Gastroenterol. 2011;4(3):177-184.

2. Ganz T, Nemeth E. Hepcidin and iron homeostasis. Biochim Biophys Acta. 2012;1823:1434-1443.

3. Weiss G. Iron metabolism in the anemia of chronic disease. Biochim Biophys Acta. 2009;1790:682-693.

4. Jhurry ND, Chakrabarti M, McCormick SP, Holmes-Hampton GP, Lindahl PA. Biophysical investigation of the ironome of human jurkat cells and mitochondria. Biochemistry. 2012;51:5276-5284.

5. Ahankari AS1, Myles PR2, Fogarty AW2, Dixit JV3, Tata LJ2. Prevalence of iron-deficiency anaemia and risk factors in 1010 adolescent girls from rural Maharashtra, India: a cross-sectional survey. Public Health. 2017 Jan;142:159-166. doi: 10.1016/j.puhe.2016.07.010. Epub 2016 Aug 31.

6. Shill KB, Karmakar P, Kibria MG, Das A, Rahman MA, Hossain MS, Sattar MM. Prevalence of iron-deficiency anaemia among university students in Noakhali region, Bangladesh. J Health Popul Nutr. 2014 Mar;32(1):103-10.

7. Miller JL. Iron deficiency anemia: a common and curable disease. Cold Spring Harb Perspect Med. ;3(7):a011866. Published . doi:10.1101/cshperspect.a011866.

8. Assessing the Iron Status of Populations. 2nd ed. Geneva, Switzerland: World Health Organization; 2007.

9. Beutler E, Waalen J. The definition of anemia: what is the lower limit of normal of the blood hemoglobin concentration? Blood. 2006;107(5):1747-1750

10. Al-alimi AA, Bashanfer S, Morish MA. Prevalence of Iron Deficiency Anemia among University Students in Hodeida Province, Yemen. Anemia. 2018; Article ID 4157876, 7 pages, 2018. https://doi.org/10.1155/2018/4157876.

11. Abdel-Rasoul GM, El Bahnasy RE, El Shazly HM, Gabr HM, AbdelAaty NB. Epidemiology of iron-deficiency anemia among primary school children (6-11 years), Menoufia governorate, Egypt. Menoufia Med J 2015;28:663-9.

Copyright: (C) the author(s), 2019. It is an open-access article distributed under the terms of the Creative Commons Attribution License (CC BY 4.0), which permits authors to retain ownership of the copyright for their content, and allow anyone to download, reuse, reprint, modify, distribute and/or copy the content as long as the original authors and source are cited.

How to cite this article: Choudhary HR, Choudhary M. A Hospital Based Prospective Study to Assess the Prevalence of Iron Deficiency Anemia among Known Population. Asian J. Med. Res. 2019;8(2):ME06-ME08.

DOI: dx.doi.org/10.21276/ajmr.2019.8.2.ME3

Source of Support: Nil, Conflict of Interest: None declared. 